\title{
Magnesium Salt Influenced Strength Behavior of Lime-Fly Ash Stabilized Fine Grained Soil
}

\author{
Zhirong JIA ${ }^{1 *}$, Luxin FU ${ }^{2}$, Lizhi WANG ${ }^{2}$ \\ ${ }^{1}$ School of Civil and Architecture Engineering, Shandong University of Technology, Zibo 255049, China \\ ${ }^{2}$ School of Transportation and Vehicle Engineering, Shandong University of Technology, Zibo 255049, China \\ crossref http://dx.doi.org/10.5755/j01.ms.26.3.21825
}

Received 13 October 2018; accepted: 26 November 2018

\begin{abstract}
The fine grained soil subgrade in coastal areas has the characteristics of high underground water level and serious salinization, and the lime-fly ash stabilized soil (LFSS) often used as the road base material. In order to study the effect of magnesium salt on the material strength, $5 \% \mathrm{MgCl}_{2}$ solution was used to simulate the groundwater magnesium salt environment, and specimens with $7 \mathrm{~d}, 14 \mathrm{~d}, 28 \mathrm{~d}, 60 \mathrm{~d}$ and $90 \mathrm{~d}$ curing ages were tested in $\mathrm{MgCl}_{2}$ solution for $1 \mathrm{~d}, 5 \mathrm{~d}$, $10 \mathrm{~d}, 15 \mathrm{~d}$ or $30 \mathrm{~d}$. A controlled test was also conducted in purified water. Strength mechanism of LFSS was analyzed; SEM test was taken; and the influence mechanism of $\mathrm{MgCl}_{2}$ medium was analyzed. The results showed that $\mathrm{MgCl}_{2}$ medium, immersing time, and curing age have effects on compressive strength of LFSS. More specifically, although the early strength is low, the strength of LFSS maintains slow and steady growth from $7 \mathrm{~d}$ to $90 \mathrm{~d}$. Long-term immersing in both $\mathrm{MgCl}_{2}$ solution and purified water will reduce the strength of LFSS, while the strength of specimen immersed in $\mathrm{MgCl}_{2}$ solution will decrease faster. Reactions between $\mathrm{MgCl}_{2}$ and LFSS destroyed the original gels and crystals, causing a negative impact on the strength of LFSS. However, with the test dose of $\mathrm{MgCl}_{2}$, the reduced strength of LFSS can still satisfy the sub-base requirement of second-class highway in China.

Keywords: pavement structure, lime-fly stabilized ash soil, stability, $\mathrm{MgCl}_{2}$, compressive strength.
\end{abstract}

\section{INTRODUCTION}

The pavement structure consists of surface layer, base layer and functional layer. Local materials are often used in the highway base course. Lime-fly stabilized ash soil (LFSS) is composed of lime, fly ash, and soil, forms a kind of load-bearing material for road structure by mixing, spreading, paving, rolling with special equipment. It is generally believed that LFSS has high strength, good integrality, and convenient construction, low cost. North of the Shandong province are vast plains, near the Bohai Gulf, with low altitude, lacking stone, LFSS often used as the road sub-base material. Local alluvial plain forms by sediment deposition of the Yellow River in Bohai depression. Its shallow groundwater is phreatic water of seawater type with highly mineralized brine, which contains $\mathrm{Mg}^{2+}, \mathrm{Cl}^{-}[1]$.

Yanggu road connects Yangxin county and G205 national highway, which is a second-class highway, and LFSS is also adopted as the sub-base material. In curing period, local LFSS was immersed in water over ten days because of the heavy rain. It was found that the local LFSS strength is obviously low, even couldn't get a complete drilling core sample (shown in Fig. 1), and couldn't meet the base acceptance standard. It is worthwhile to study how the strength of LFSS is changed while water or erosive groundwater are affected.

The intensity characteristics of cement soil, lime soil are studied in water environment or erosive environment in recent years. Mechanical properties of cement soil are affected by several factors, such as cement content, curing time, moisture content, compaction characteristics, aggregate gradation, quality of aggregates and additives [2-4]. Over-rich cement layers are instead too stiff and prone to shrinkage cracking, causing accelerated pavement failure [5,6]. Nano- $\mathrm{CaCO}_{3}$ addition can improve the compressive strength of cement-stabilized soil and reduce the corrosion speed and increase the compaction degree of cement-stabilized soil in marine environment [7].

Chlorine salt has various effects on lime-treated soil according to literatures. $\mathrm{MgCl}_{2}$ solution does not damage cement soil, which has long been used to de-ice roads in regions that experience harsh winters $[8,9]$, and $\mathrm{MgCl}_{2}$ has the capacity to retain the absorbed moisture for an extended period of time [10]. $\mathrm{MgCl}_{2}$ improves the compressive strength of the bentonite and kaolin significantly in that pores of the soils have been filled by newly formed crystalline compounds known as magnesium silicate hydrate (M-S-H) and magnesium aluminate hydrate (M-A$\mathrm{H})$ respectively [11]. Chlorine salt has obvious effects on the structure of the lime-treated soil [12]. The chlorine salt induces engineering problems in the lime-treated soil, which affect its stability, especially when the salt content is more than $3.0 \%$ [13]. Salt ions can enter into charged porous media and then react with the soil particles [14]. Chlorine ions also have a higher hydration radius and could absorb water $[13,15]$, and have a negative effect on the strength of treated soil in the short and long term [16].

As to LFSS, researches are mainly focused on LFSS mix proportion, dynamic property, compaction parameter, etc $[17-19]$. There are lack of research on the effects of underground water, especially the magnesium salt erosion medium.

\footnotetext{
${ }^{*}$ Corresponding author. Tel.: +86-151-6922-7677;
}

E-mail address: jiazhr@126.com (Z.Jia) 


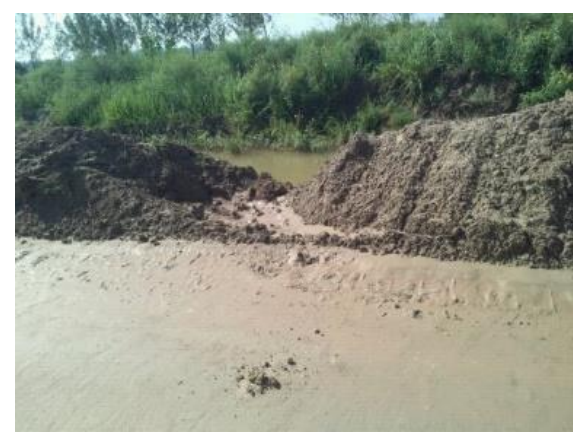

a

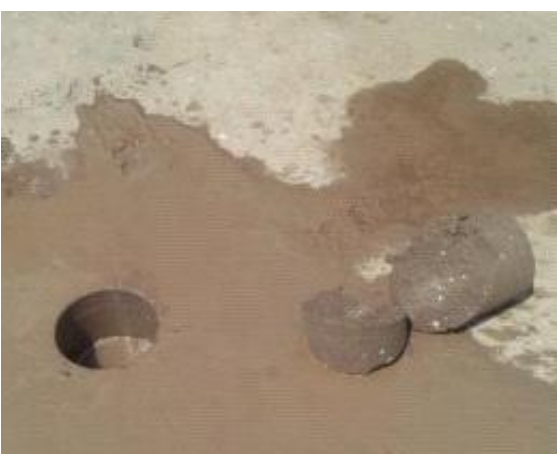

$\mathrm{b}$

Fig. 1. Road base: $a$-after immersing, $b$ - fractured core sample

Through evaluating the effects of $\mathrm{MgCl}_{2}$, this paper makes a research on the mechanical property and strength mechanism of lime-fly ash stabilized soil under special environment.

\section{RAW MATERIAL}

The experimental soil was taken from Laodian town, Yangxin county, Shandong province. It is silty clay, with a plastic limit of 19.6, liquid limit of 34.9, plasticity index of 15.3 , natural density of $1.64 \mathrm{~g} / \mathrm{cm}^{3}$, and the soil moisture content is $16.18 \%$.

The test lime was purchased locally. The content of $\mathrm{CaO}+\mathrm{MgO}$ is more than $90 \%$, which is calcareous calcium lime and high class product. Fly ash was gotten from Zou county Huadian power plant, grade A. Fly ash main indicators are shown in Table 1, and its chemical composition $\left(\mathrm{SiO}_{2}, \mathrm{Al}_{2} \mathrm{O}_{3}\right.$ and $\left.\mathrm{Fe}_{2} \mathrm{O}_{3}\right)$ account for more than $80 \%$ of the total composition. The additive cement is 42.5 sulfate-resistant silicate cement which purchased from Zibo zhongchang special cement company, the main indexes are listed in Table 2. The raw materials meet the technical specification requirements $[20,21]$.

\section{EXPERIMENT}

\subsection{Mix proportion and specimen molding}

Mixture ratio design based on JTG D50 Specifications for Design of Highway Asphalt Pavement and JTJ E51 Test Methods of Materials Stabilized with Inorganic Binders for Highway Engineering and engineering experience. In order to make the LFSS representative, local frequently-used mixture ratio was chosen. The mass ratio of lime, fly ash and soil was intended to be 10:20:70, with additives cement $5 \%$.
Lime and fly-ash are inorganic binders for fine soil, and cement can improve the early strength.

The maximum dry density was $1.785 \mathrm{~g} / \mathrm{cm}^{3}$, and the optimum moisture content was $21.8 \%$. Cylindrical specimens, 6 for each group, with a total of 228 were molded into $50 \mathrm{~mm}$ high and $50 \mathrm{~mm}$ diameter through static pressure molding method [20].

In order to reduce the production method, production equipment, raw materials, curing condition and other factors on the experimental results, all specimens were made in one time.

\subsection{Maintenance method}

Adopt standard maintenance condition (temperature $20 \pm 2{ }^{\circ} \mathrm{C}$, relative humidity $95 \%$ ), maintain different days, and immerse different time in purified water and $\mathrm{MgCl}_{2}$ solution.

Two groups of specimens with different curing ages were cured in standard condition (temperature $20 \pm 2{ }^{\circ} \mathrm{C}$, humidity above $95 \%$ ) for $2 \mathrm{~d}-89 \mathrm{~d}$, and then immersed in purified water or $\mathrm{MgCl}_{2}$ solution for $1 \mathrm{~d}$ to $30 \mathrm{~d}$ respectively.

Four groups of 24 specimens of $7 \mathrm{~d}$ curing age were cured in standard condition for $6 \mathrm{~d}$ and $2 \mathrm{~d}$, and then immersed in purified water or $\mathrm{MgCl}_{2}$ solution or for $1 \mathrm{~d}$ and $5 \mathrm{~d}$ respectively; six groups of 36 specimens of $14 \mathrm{~d}$ curing age were cured in standard condition for $13 \mathrm{~d}, 9 \mathrm{~d}$ and $4 \mathrm{~d}$, and then immersed in purified water or $\mathrm{MgCl}_{2}$ solution or for $1 \mathrm{~d}, 5 \mathrm{~d}$ and $10 \mathrm{~d}$ respectively; eight groups of 48 specimens of $28 \mathrm{~d}$ curing age were cured in standard condition for $27 \mathrm{~d}, 23 \mathrm{~d}, 18 \mathrm{~d}$, and $13 \mathrm{~d}$, and then immersed in purified water or $\mathrm{MgCl}_{2}$ solution or for $1 \mathrm{~d}, 5 \mathrm{~d}, 10 \mathrm{~d}$, and $15 \mathrm{~d}$ respectively; ten groups of 60 specimens of $60 \mathrm{~d}$ curing age were cured in standard condition for $59 \mathrm{~d}, 55 \mathrm{~d}, 50 \mathrm{~d}$, $45 \mathrm{~d}$, and $30 \mathrm{~d}$, and then immersed in purified water or $\mathrm{MgCl}_{2}$ solution or for $1 \mathrm{~d}, 5 \mathrm{~d}, 10 \mathrm{~d}, 15 \mathrm{~d}$, and $30 \mathrm{~d}$ respectively; ten groups of 60 specimens of $90 \mathrm{~d}$ curing age were cured in standard condition for $89 \mathrm{~d}, 85 \mathrm{~d}, 80 \mathrm{~d}, 75 \mathrm{~d}$, and $60 \mathrm{~d}$, and then immersed in purified water or $\mathrm{MgCl}_{2}$ solution or for $1 \mathrm{~d}, 5 \mathrm{~d}, 10 \mathrm{~d}, 15 \mathrm{~d}$, and $30 \mathrm{~d}$ respectively.

\subsection{Compression strength}

Take LFSS specimens out of $\mathrm{MgCl}_{2}$ solution and purified water at the scheduled time, dry the specimen surface, and test the unconfined compressive strengths. Eliminate the outliers using triple mean square error method, and take the unconfined compressive strength of $95 \%$ assurance rate as the compressive strength of a group of specimens. The compressive strengths of different curing, immersing ages and different immersion medium are shown in Table 3.

\section{DATA ANALYSIS}

\subsection{Strength growth pattern of LFSS}

Specimens are cured in standard condition, then immersed in purified water at the last day, and test the unconfined compressive strengths. The growth rule of the strength of LFSS specimens cured in standard condition is shown in Fig. 2. 
Table 1.Chemical compositions and physical indexes of the fly ash

\begin{tabular}{|c|c|c|c|c|c|c|c|c|c|}
\hline \multicolumn{7}{|c|}{ Chemical compositions, $\%$} & \multirow{2}{*}{$\begin{array}{c}\text { Loss on } \\
\text { ignition, } \% \\
\end{array}$} & \multirow{2}{*}{$\begin{array}{c}\text { Moisture } \\
\text { content, \% } \\
\end{array}$} & \multirow{2}{*}{$\begin{array}{c}45 \mu \mathrm{m} \text { screen } \\
\text { residue, } \%\end{array}$} \\
\hline $\mathrm{SiO}_{2}$ & $\mathrm{Al}_{2} \mathrm{O}_{3}$ & $\mathrm{CaO}$ & $\mathrm{Fe}_{2} \mathrm{O}_{3}$ & $\mathrm{~K}_{2} \mathrm{O}$ & $\mathrm{SO}_{3}$ & $\mathrm{Cl}^{-}$ & & & \\
\hline 53.52 & 34.26 & 5.84 & 3.10 & 1.43 & 1.58 & 0.01 & 1.89 & 0.10 & 10.00 \\
\hline
\end{tabular}

Table 2. Main indicators of cement

\begin{tabular}{|c|c|c|c|c|c|c|c|c|c|c|c|c|}
\hline \multicolumn{5}{|c|}{ Chemical compositions, $\%$} & \multirow{2}{*}{$\begin{array}{c}\text { Specific } \\
\text { surface } \\
\text { area, } \\
\mathrm{m}^{2} / \mathrm{kg} \\
\end{array}$} & \multirow{2}{*}{$\begin{array}{c}14 \mathrm{~d} \text { linear } \\
\text { expansivity, \% }\end{array}$} & \multicolumn{2}{|c|}{$\begin{array}{c}\text { Setting time, } \\
\text { min }\end{array}$} & \multicolumn{2}{|c|}{$\begin{array}{c}\text { Flexural } \\
\text { strength, } \mathrm{MPa} \\
\end{array}$} & \multicolumn{2}{|c|}{$\begin{array}{l}\text { Compressive } \\
\text { strength, MPa }\end{array}$} \\
\hline $\mathrm{C}_{3} \mathrm{~S}$ & $\mathrm{C}_{3} \mathrm{~A}$ & $\mathrm{MgO}$ & $\mathrm{SO}_{3}$ & Alkali & & & Initial & Final & $3 \mathrm{~d}$ & $28 \mathrm{~d}$ & $3 \mathrm{~d}$ & $28 \mathrm{~d}$ \\
\hline 44.30 & 2.70 & 3.00 & 1.80 & 0.55 & 378 & 4.7 & 204 & 285 & 5.0 & 7.7 & 27.6 & 47.2 \\
\hline
\end{tabular}

Table 3. Compressive strengths of LFSSspecimens

\begin{tabular}{|c|c|c|c|c|c|c|}
\hline \multirow{2}{*}{ Curing time, $\mathrm{d}$} & \multirow{2}{*}{ Immerse medium } & \multicolumn{5}{|c|}{ Unconfined compressive strength, MPa and immersing time, $\mathrm{d}$} \\
\hline & & 1 & 5 & 10 & 15 & 30 \\
\hline \multirow{2}{*}{7} & $5 \% \mathrm{MgCl}_{2}$ & 1.1 & 0.9 & - & - & - \\
\hline & Water & 1.2 & 1.1 & - & - & - \\
\hline \multirow{2}{*}{14} & $5 \% \mathrm{MgCl}_{2}$ & 1.6 & 1.5 & 1.4 & - & - \\
\hline & Water & 1.6 & 1.6 & 1.5 & - & - \\
\hline \multirow{2}{*}{28} & $5 \% \mathrm{MgCl}_{2}$ & 2.2 & 2.0 & 1.7 & 1.8 & - \\
\hline & Water & 2.1 & 2.0 & 2.1 & 1.9 & - \\
\hline \multirow{2}{*}{60} & $5 \% \mathrm{MgCl}_{2}$ & 2.8 & 2.5 & 2.4 & 2.4 & 2.1 \\
\hline & Water & 2.9 & 2.6 & 2.7 & 2.6 & 2.5 \\
\hline \multirow{2}{*}{90} & $5 \% \mathrm{MgCl}_{2}$ & 3.4 & 3.1 & 2.7 & 2.7 & 2.4 \\
\hline & Water & 3.3 & 3.0 & 2.9 & 2.8 & 2.7 \\
\hline
\end{tabular}

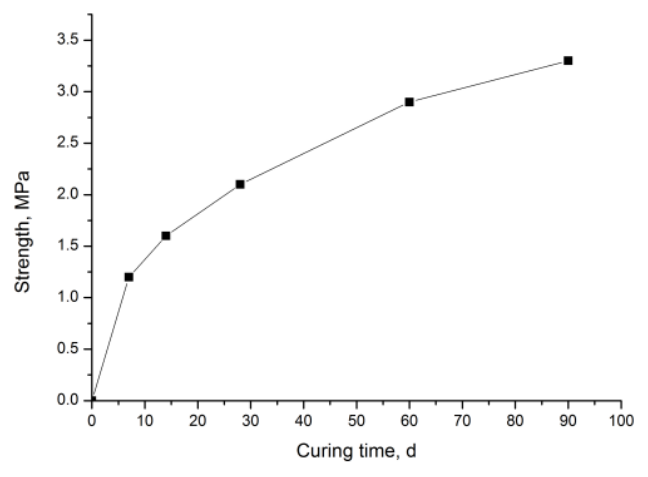

Fig. 2. Growth curve in standard curing condition

As shown in Fig. 2, the early strength of LFSS $(0-7 \mathrm{~d})$ is very low in the standard curing condition, but grows fast. The strength continues to maintain slow and steady growth from $7 \mathrm{~d}$ to $90 \mathrm{~d}$.

\subsection{Growth pattern of strength effected by $\mathrm{MgCl}_{2}$}

The change of the specimen compressive strengths immersed in $\mathrm{MgCl}_{2}$ solution for different curing and immersing ages is shown in Fig. 3, and that immersed in purified water is shown in Fig. 4.

As shown in Fig 3, the compressive strength of the specimens after immersing in the $\mathrm{MgCl}_{2}$ solution is reduced to a certain extent, and the compressive strength of the specimens is roughly linear. The longer the immersing time is, the greater the reduction of compressive strength is. The compressive strength of the specimens in the $90 \mathrm{~d}$ phase after immersing $5 \mathrm{~d}, 10 \mathrm{~d}, 15 \mathrm{~d}$ and $30 \mathrm{~d}$ in $\mathrm{MgCl}_{2}$ solution decrease by $8.8 \%, 20.6 \%, 20.6 \%$ and $29.4 \%$ respectively. The first $5 \mathrm{~d}$ decreases significantly, and the overall decline is slow. See Table 4 for the maximum strength of the specimens in two immersion environments.

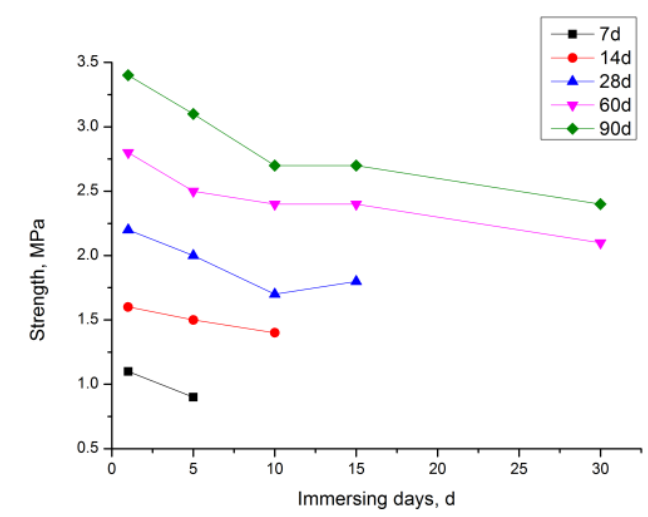

Fig. 3. Compressive strengths of specimens immersed in $\mathrm{MgCl}_{2}$ solution

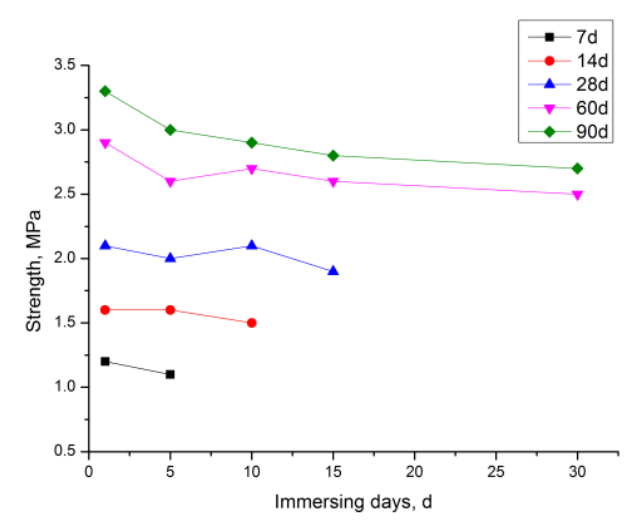

Fig. 4. Compressive strengths of specimens immersed in water 
As shown in Fig. 4, with the increase of immersing days, compressive strength of the control group specimens immersed in water fell roughly the same as immersed in $\mathrm{MgCl}_{2}$ solution. With the increase of immersion time, LFSS compressive strength is reduced. The compressive strength of $90 \mathrm{~d}$ specimens after immersing $5 \mathrm{~d}, 10 \mathrm{~d}, 15 \mathrm{~d}$ and $30 \mathrm{~d}$ in purified water decreased by $9.1 \%, 12.1 \%, 15.2 \%$ and $18.2 \%$ respectively. However, in the intensity reduction range, specimens immersed in $\mathrm{MgCl}_{2}$ solution declined even more. As can be seen from Table 4, immersion in $\mathrm{MgCl}_{2}$ solution decreased by $6.2-13.2 \%$ compared with immersion in water.

The $7 \mathrm{~d}$ strength is greater than $0.7 \mathrm{MPa}$, although the strength decreases after immersing, still meet the sub-base requirement of second-class highway in China [21]. It is also indicated that $\mathrm{MgCl}_{2}$ is not the main cause of sub-base quality problem at Yanggu road. Magnesium salt has negative effect on LFSS strength, but the effect degree is limited, not fatal. It means that further study should be taken to justify the influence of other harmful ions.

Table 4. Compressive strengths of LFSS specimens

\begin{tabular}{|c|c|c|c|c|c|}
\hline \multirow{2}{*}{$\begin{array}{c}\text { Immerse } \\
\text { medium }\end{array}$} & \multicolumn{5}{|c|}{ Strength decline rate, \% } \\
\cline { 2 - 6 } & $7 \mathrm{~d}$ & $14 \mathrm{~d}$ & $28 \mathrm{~d}$ & $60 \mathrm{~d}$ & $90 \mathrm{~d}$ \\
\hline $5 \% \mathrm{MgCl}_{2}$ & 18.2 & 12.5 & 22.7 & 25.0 & 29.4 \\
\hline Water & 8.3 & 6.3 & 9.5 & 13.8 & 18.2 \\
\hline
\end{tabular}

\section{MECHANISM ANALYSIS}

\subsection{Strength formation mechanism}

Physical and chemical reactions occur in LFSS when water is added. Ion exchange reaction make soil particles closer, improve the soil compactness. Crystallization and carbonation reactions, shown as Eq. 1, Eq. 2, produce calcium hydroxide and calcium carbonate crystals. Pozzolanic reaction, shown as Eq. 3, Eq. 4, produces hydrated calcium silicate and hydrated calcium aluminate gelatinous substances, that is the main cause of soil strength and water stability. New crystals and gelatinous substances fill the soil particle voids and produce binder among them, improves the soil strength, and reduce the porosity and water permeability of LFSS [17, 22].

$$
\begin{aligned}
& \mathrm{Ca}(\mathrm{OH})_{2}+n \mathrm{H}_{2} \mathrm{O} \rightarrow \mathrm{Ca}(\mathrm{OH})_{2} \cdot n \mathrm{H}_{2} \mathrm{O} ; \\
& \mathrm{Ca}(\mathrm{OH})_{2}+\mathrm{CO}_{2} \rightarrow \mathrm{CaCO}_{3}+\mathrm{H}_{2} \mathrm{O} ; \\
& x \mathrm{Ca}(\mathrm{OH})_{2}+\mathrm{SiO}_{2}+n \mathrm{H}_{2} \mathrm{O} \rightarrow x \mathrm{CaO} \cdot \mathrm{SiO}_{2}(\mathrm{n}+1) \mathrm{H}_{2} \mathrm{O} ; \\
& x \mathrm{Ca}(\mathrm{OH})_{2}+\mathrm{Al}_{2} \mathrm{O}_{3}+n \mathrm{H}_{2} \mathrm{O} \rightarrow x \mathrm{CaO} \cdot \mathrm{Al}_{2} \mathrm{O}_{3}(\mathrm{n}+1) \mathrm{H}_{2} \mathrm{O} .
\end{aligned}
$$

\subsection{The effect of water on the strength of the LFSS}

Lime solution diluted in the water curing condition, and calcium ion concentration reduced when calcium ion dissociating from lime solution. That slow down the ion exchange velocity, abate the hardening effect and carbonation reaction, and then effect the strength of LFSS. $\mathrm{Ca}(\mathrm{OH})_{2}$ and $\mathrm{CaCO}_{3}$ crystals will dissolve in water at a certain degree, undissolved $\mathrm{CaO}$ will swell, excessive moisture also reduces friction between soil particles, these factors will lead to the intensity change of LFSS.

\subsection{The effect of $\mathrm{MgCl}_{2}$ on the strength of LFSS}

The chemical reactions between $\mathrm{MgCl}_{2}$ and LFSS are shown as Eq. 5 -Eq. 9.

$$
\begin{aligned}
& \mathrm{MgCl}_{2}+\mathrm{Ca}(\mathrm{OH})_{2} \rightarrow \mathrm{CaCl}_{2}+\mathrm{Mg}(\mathrm{OH})_{2} ; \\
& 3 \mathrm{CaO} \cdot 2 \mathrm{SiO}_{2} \cdot 3 \mathrm{H}_{2} \mathrm{O}(\mathrm{C}-\mathrm{S}-\mathrm{H})+3 \mathrm{MgCl}_{2}+9 \mathrm{H}_{2} \mathrm{O} \\
& \rightarrow 3 \mathrm{CaCl}_{2} \cdot 6 \mathrm{H}_{2} \mathrm{O}+3 \mathrm{Mg}(\mathrm{OH})_{2}+2 \mathrm{SiO}_{2} ; \\
& \mathrm{Mg}(\mathrm{OH})_{2}+\mathrm{SiO}_{2} \rightarrow \mathrm{MgO} \cdot \mathrm{SiO}_{2} \cdot \mathrm{H}_{2} \mathrm{O}(\mathrm{M}-\mathrm{S}-\mathrm{H}) ; \\
& 3 \mathrm{CaO} \cdot \mathrm{Al}_{2} \mathrm{O}_{3} \cdot 6 \mathrm{H}_{2} \mathrm{O}(\mathrm{C}-\mathrm{A}-\mathrm{H})+3 \mathrm{MgCl}_{2}+9 \mathrm{H}_{2} \mathrm{O} \\
& \rightarrow 3 \mathrm{CaCl}_{2} \cdot 6 \mathrm{H}_{2} \mathrm{O}+3 \mathrm{Mg}(\mathrm{OH})_{2}+\mathrm{Al}_{2} \mathrm{O}_{3} ; \\
& \mathrm{Mg}(\mathrm{OH})_{2}+\mathrm{Al}_{2} \mathrm{O}_{3} \rightarrow \mathrm{MgO} \cdot \mathrm{Al}_{2} \mathrm{O}_{3} \cdot \mathrm{H}_{2} \mathrm{O}(\mathrm{M}-\mathrm{A}-\mathrm{H}) .
\end{aligned}
$$

After the chemical reaction between magnesium chloride and calcium hydroxide crystal, shown as Eq. 5, the newly generated $\mathrm{Mg}(\mathrm{OH})_{2}$ is looser than the original $\mathrm{Ca}(\mathrm{OH})_{2}$, and the coagulation force is poor, which result in strength decrease of LFSS. The chemical reaction between magnesium chloride and C-S-H gel in LFSS, shown as Eq. 6, generates calcium chloride crystal $\left(\mathrm{CaCl}_{2} \cdot 6 \mathrm{H}_{2} \mathrm{O}\right)$, brucite $\left(\mathrm{Mg}(\mathrm{OH})_{2}\right)$ and free silica $\left(\mathrm{SiO}_{2}\right)$. At the same time, the reaction of hydromagnesite and free quartz is further developed, shown as Eq. 7, generates M-S-H which difficult to dissolve in water. The chemical reaction between magnesium chloride and $\mathrm{C}-\mathrm{A}-\mathrm{H}$ gel, shown as Eq. 7 and Eq. 8, generates M-A-H. Newly generated M-S-H and M-A$\mathrm{H}$ have lower bonding strength than $\mathrm{C}-\mathrm{S}-\mathrm{H}$, and disperse in LFSS. Those results in poor cementation and reduce the structural strength of LFSS $[8,22]$.

After immersing in $\mathrm{MgCl}_{2}$ solution, lots of white mineral crystals are produced, whichare mainly $\mathrm{Mg}(\mathrm{OH})_{2}$, as shown in Fig. 5. Newly generated minerals will also gradually absorb water and expand, resulting in internal stress.

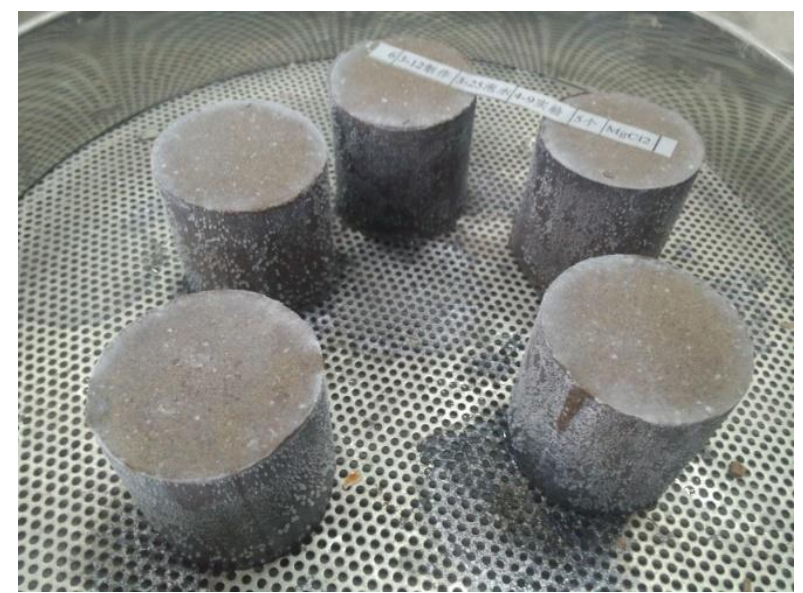

Fig. 5. Photo of specimen immersed in $\mathrm{MgCl}_{2}$ solution for $15 \mathrm{~d}$

At the same time, the generation of $\mathrm{Mg}(\mathrm{OH})_{2}$ consumes the $\mathrm{OH}^{-}$in the pore fluid, reduces the $\mathrm{pH}$ value. In order to maintain the balance, calcium silicate and hydrated aluminate are decomposed into $\mathrm{Ca}(\mathrm{OH})_{2}$, resulting in solid phase decomposition and loose structure.

Chloride ions have some interference effects. The chloride ions can increase the solubility of calcium sulphoaluminate and inhibit the sulfate erosion. In the case of $\mathrm{SO}_{4}{ }^{2-}$ ions, chloride ions have a certain protective effect on the LFSS. Without $\mathrm{SO}_{4}{ }^{2-}$ ions, the negative effect of 
chloride ions on strength is relatively small [23].

As the SEM photo presented in Fig. 6 and Fig. 7, less amount of needle and plate saline mineral crystals are produced in LFSS specimens immersed in $\mathrm{MgCl}_{2}$ solution for 7 and 14 days, and the structure is looser than that of specimens immersed in water.

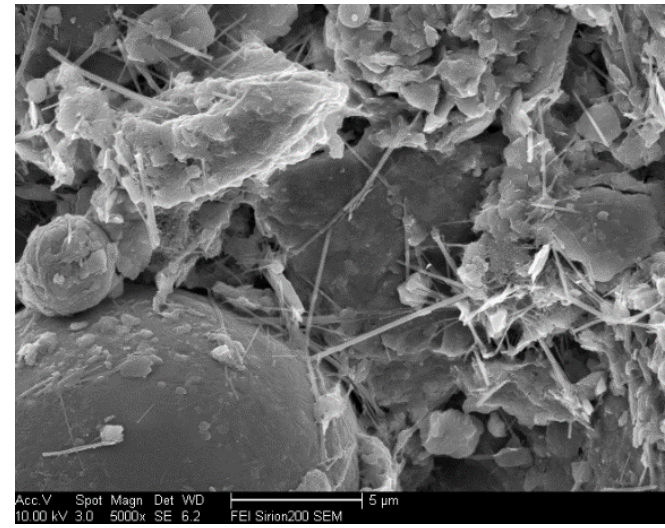

a

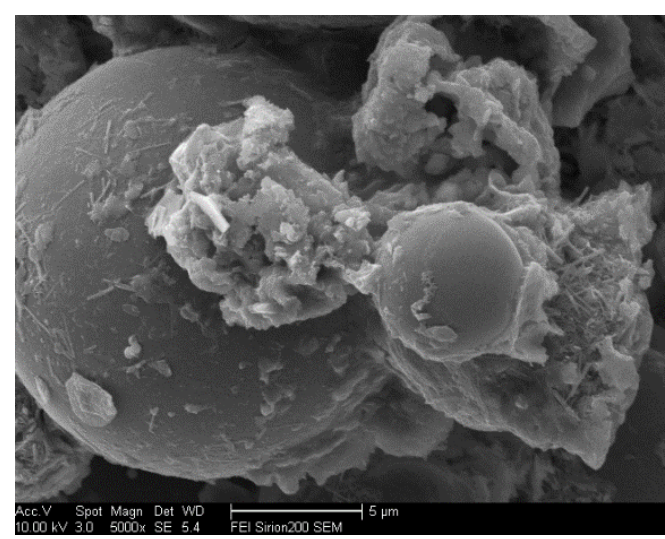

b

Fig. 6. SEM photo of $7 \mathrm{~d}$ specimens: a-immersed in water; $\mathrm{b}-\mathrm{MgCl}_{2}$ solution

\section{CONCLUSIONS}

1. The early compressive strength of LFSS is low in the standard curing conditions, but grows fast. The strength continues to maintain slow and steady growth from $7 \mathrm{~d}$ to $90 \mathrm{~d}$.

2. The compressive strength of LFSS specimens will decrease with immersing time both in $\mathrm{MgCl}_{2}$ solution and purified water. The longer the immersing time, the more the compressive strength decreases.

3. The strength of LFSS immersed in $\mathrm{MgCl}_{2}$ solution will reduce more significantly than that in purified water when the curing age and immersing time are same.

4. The influenced strength of LFSS can still satisfy the sub-base requirement of second-class highway in China under limited immersing time both in $\mathrm{MgCl}_{2}$ solution and purified water.

5. The negative effects of $\mathrm{MgCl}_{2}$ are mainly caused by the change of gel and crystal types of cementation in LFSS.
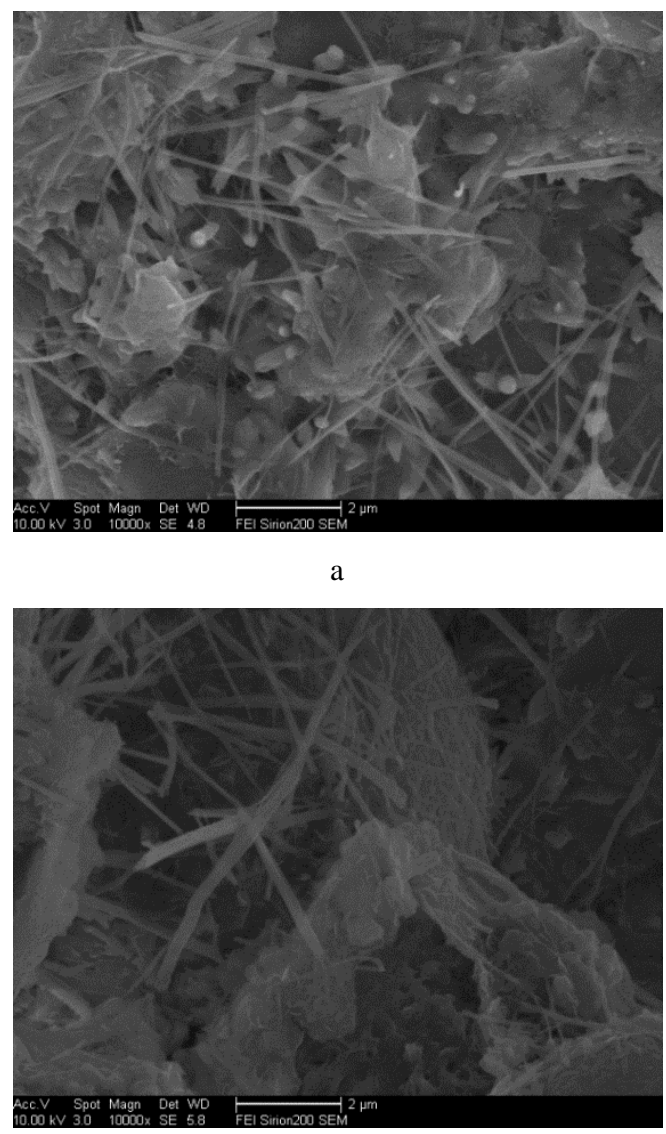

b

Fig. 7. SEM photo of $14 \mathrm{~d}$ specimens: a-immersed in water; $\mathrm{b}-\mathrm{MgCl}_{2}$ solution

\section{Data availability}

The data used to support the findings of this study are available from the corresponding author upon request.

\section{REFERENCES}

1. Fu, T.F., Zhang, Y., Gao, J.W., Chen, G.Q., Liu, W.Q., Su, Q. Study on Spatio-temporal Variability of Saline Soil Salinity in the Yellow River Delta Periodical of Ocean University of China 47 (10) 2017: pp. 50-60.

https://doi.org/10.16441/j.cnki.hdxb.20160476

2. Liu, Z.P. Laboratory Test of Mechanical Properties of Cemented Soil under Brine Corrosion Environment and Durability Analysis, Wuhan University, Wuhan, 2013.

3. Harichane, K., Ghrici, M., Kenai, S. Stabilization of Algerian Clayey Soils with Natural Pozzolana and Lime Periodica Polytechnica Civil Engineering 62(1) 2018: pp. $1-10$. https://doi.org/10.3311/PPci.9229

4. Behnood, A. Soil and Clay Stabilization with Calcium- and Non-Calcium-Based Additives: A State-of-the-Art Review of Challenges, Approaches and Techniques Transportation Geotechnics 17 (12) 2018: pp. 14-32. https://doi.org/10.1016/j.trgeo.2018.08.002

5. Autelitano, F., Giuliani, F. Electric Arc Furnace Slags in Cement-Treated Materials for Road Construction: Mechanical and Durability Properties Construction and Building Materials 113 (3) 2016: pp. 280-289. https://doi.org/10.1016/j.conbuildmat.2016.03.054 
6. Xuan, D.X., Houben, L.J.M., Molenaar, A.A.A., Shu, Z.H. Mechanical Properties of Cement-Treated Aggregate Material - A Review Materials and Design 33 (1) 2012: pp. 496-502.

https://doi.org/10.1016/j.matdes.2011.04.055

7. Meng, T., Qiang, Y.J., Hu, A.F., Xu, C.T., Lin, L. Effect of Compound Nano- $\mathrm{CaCO}_{3}$ Addition on Strength Development and Microstructure of Cement-Stabilized Soil in the Marine Environment Construction and Building Materials 151 (10) 2017: pp. $775-781$.

https://doi.org/10.1016/j.conbuildmat.2017.06.016

8. Han, P.J., Zhang, W.B., Liu, X., Bai, X.H. Early Strength of Cemented Soils Polluted by Magnesium Chloride Chinese Journal of Geotechnical Engineering $36(6)$ 2014: pp. $1173-1178$. https://doi.org/10.11779/CJGE201406025

9. Canadian Environmental Protection Act, 1999: Priority Substance List Assessment Report-Road Salts, Environmental Canada, Quebec, 2001.

10. Turkoz, M., Savas, H., Acaz, A., Tosun, H. The effect of Magnesium Chloride Solution on the Engineering Properties of Clay Soil with Expansive and Dispersive Characteristics Applied Clay Science 101 (11) 2014: pp. 1-9. https://doi.org/10.1016/j.clay.2014.08.007

11. Latifia, N., Rashid, A.S.A., Siddiqua, S., Horpibulsuk, S. Micro-Structural Analysis of Strength Development in Low and High Swelling Clays Stabilized with Magnesium Chloride Solution-A Green Soil Stabilizer Applied Clay Science 118 (12) 2015: pp. 195-206. https://doi.org/10.1016/j.clay.2015.10.001

12. Liu, Q.S., Qu, J.W., He, J. Experimental Study of Mechanical Properties of Cemented Soil under Corrosion Influence Rock and Soil Mechanics 35 (12) 2014: pp. $3377-3384$. https://doi.org/10.16285/j.rsm.2014.12.012

13. Li, M., Chai, S., Du, H., Wang, C. Effect of Chlorine Salt on the Physical and Mechanical Properties of Inshore Saline Soil Treated with Lime Soils and Foundations $56(3)$ 2016: pp. $327-335$. https://doi.org/10.1016/j.sandf.2016.04.001
14. Koniorczyk, M. Salt Transport and Crystallization in Nonisothermal Partially Saturated Porous Materials Considering Ions Interaction Model International Journal of Heat \& Mass Transfer 55 (4) 2012: pp. 665-679.

https://doi.org/10.1016/j.ijheatmasstransfer.2011.10.043

15. Flatt, R.J. Salt Damage in Porous Materials: How High Supersaturation Is Generated Journal of Crystal Growth 242 (3-4) 2002: pp. 435-454.

https://doi.org/10.1016/S0022-0248(02)01429-X

16. Carteret, R.D., Buzzi, O., Fityus, S., Liu, X.F. Effect of Naturally Occurring Salts on Tensile and Shear Strength of Sealed Granular Road Pavements Journal of Materials in Civil Engineering 26 (6) 2013: pp. 1-13. https://doi.org/10.1061/(ASCE)MT.1943-5533.0000938

17. Wang, H.F. Experiment and Application Research on Factors to Influence Formation of Lime-Ash Soil Strength, Nanjing Forestry University, Nanjing, 2007.

18. Yu, X.S. Laboratory Test Study on Strength Evolutionary Rules of the Evolution of Lime-Fly Ash Aeolian Soil Subgrade under Complex Stress, Liaoning Technical University, Fujian, 2013.

19. Shang, Q.S., Liu, S.T. Analysis about the Factors Influence the Strength of Fine Grained Soil Stabilized by Lime and Lime-Ash Journal of Highway and Transportation Research and Development 17 (6) 2000: pp. 26-29. http://worldcat.org/issn/10020268

20. JTG/T F20-2015, Technical Guidelines for Construction of Highway Roadbases, China Communications Press, Beijing, 2015 .

21. JTG D50-2017, Specifications for Design of Highway Asphalt Pavement, China Communications Press, Beijing, 2017.

22. Wang, H. Y. Experiment and Application Research on Factors to Influence Formation of Lime-Ash Soil Strength, Beijing Forestry University, Beijing, 2007.

23. Guo, K.M., Guo, G.Y., Liu, X.L. Research on the Influence of the Chloride Ion to Performance of the Lime and Flushed by Seawater Stabilized Soil Journal of Low Temperature Architecture Technology 35 (02) 2013: pp. 8-10. 